\title{
Post-Mortem Infarction Diagnosis Using Molecular Techniques
}

Koutsoukis $\mathbf{S}^{1}$, Chatzifotiou $E^{1}$, Nikolaou $A^{1}$, Fiska $A^{2}$, Anestakis $D^{1^{*}}$, Raikos $\mathbf{N}^{1}$, Pavlidis $\mathbf{P}^{3}$

${ }^{1}$ Laboratory of Forensic Medicine and Toxicology, School of Medicine, Aristotle University of Thessaloniki, GR 54124, Thessaloniki, Greece

${ }^{2}$ Department of Anatomy, School of Medicine, Democritus University of Thrace, Dragana, GR 68100, Alexandroupolis, Greece

${ }^{3}$ Laboratory of Forensic Sciences, School of Medicine, Democritus University of Thrace, Dragana, GR 68100, Alexandroupolis, Greece

*Corresponding author: Anestakis Doxakis, Department of Forensic Medicine and Toxicology, School of Medicine, Aristotle University of Thessaloniki, GR 54124, Thessaloniki, Greece, Tel: +306972697072; E-mail: anestaki@auth.gr

Received date: August 29, 2018; Accepted date: October 16, 2018; Published date: October 23, 2018

Copyright: (c) 2018 Koutsoukis S, et al. This is an open-access article distributed under the terms of the Creative Commons Attribution License, which permits unrestricted use, distribution, and reproduction in any medium, provided the original author and source are credited.

\section{Abstract}

The cardiovascular system plays a major role in life. From the past up to now, one of the main causes of death is cardiac infarction. Heart is the most important organ of this system and its function is to transfer blood and its contents to the whole body. There is a direct line through pulmonary artery to the lungs, so blood can be fleshed out with oxygen.

Infarction is a severe damage in a localized site of the heart, which leads to that part's necrosis. There are symptoms reported, such as discomfort, ache and others that are analysed below.

Post-mortem examination of the cardiac muscle is a basic way to find out information about infarction. There are alterations, depended on the time between the infarction and the observation of the heart. Nowadays, science and technology progress allows us to use molecular biology techniques as a tool to be accurate and detailed about diagnosis. There are dilutions and machinery which can save time and provide results beyond a doubt. Immunohistochemistry and Real Time Polymerase Chain Reaction are such techniques, which can detect and quantify the class of infarction. These techniques are analysed below, including with some subcategories of the ways we can use them.

Keywords: Post mortem; Infarction; Real time PCR; Cardiac; Heart

\section{Introduction}

In order to understand, it is important to know a few things about heart, such as the anatomy, the physiology and the histology of the cardiac muscle. It is the main organ of the cardiovascular system and it works as a pumper. It is surrounded by pericardium and its inner part (myocardium) has four cavities (atria and ventricles), covered by endocardium. These cavities are located on the right and left sight of the myocardium. Cardiac muscle is externally divided into anterior (or lateral), diaphragmatic and posterior, which is also called "base of the heart" [1-6].

According to physiology, heart is the main organ of the circular process of transferring blood and its contents. Blood enters the cardiac muscle from the right atrium, from where it moves to the right ventricle, and then it moves to lungs, where it is enriched with oxygen. After this process, blood enters the left atrium and it moves to the left ventricle, from where it enters the circulation. The prevention of blood reflux is achieved by the valves. This whole process is coordinated by myocardial contractions, which are the heart rate, determined by electrical currents produced by specialized cells in specialized tissues and transported through a network of specialized fibers, which is called "system of production and stimulation". This system works through dynamic action [7-12].

The histologic view of the heart is more microscopic. During fetal age, a blood vessel shaper maintains three tunics that enclose, resulting three layers. Mesothelial cells create a smooth surface that forms the epicardium. Muscle cells form muscle fibres, forming the myocardial and endothelial cells and endothelial cells dorm the endocardium in the form of a smooth lining. Cardiac muscle is a striated muscle, composed by muscle fibres, myofibrils, muscle filaments and transverse striations. Monocytes have a nucleus, they are branched out and their final parts join together to create elongated cardiac fibers. Their lateral sides are joined together at specific locations. Myocardial cells are sited as a layer composite formed and three-dimensional spiral shape to form an anastomotic communication network from relevant neighbouring cells. The proper blood circulation is achieved by the synchronized contraction of these adjacent cells [13-17].

\section{Infarction}

Myocardial infarction is a worldwide leading death among all cardiovascular diseases. It reflects a prolonged localized ischemic necrosis site, an irreparable myocardial damage usually due to atherosclerotic stenosis of a large coronary artery. As a result of imbalance between supply and demand deaths of myocardial cells caused. The range and the position of thrombus varies. Possible ischemic symptoms include diffuse discomfort, dispone, diaphoresis, nausea, arrhythmia or syncope. Myocardial infarction may be defined from clinical, electrocardiographic, biochemical, imaging and pathological characteristics. Nevertheless asymptomatic cases can also occur [18-27].

Universal classification of myocardial infarction consists of five types: Spontaneous myocardial infarction (Type 1), Myocardial infarction secondary to an ischemic imbalance (Type 2), Myocardial 
infarction resulting in death when biomarker values are unavailable (Type 3), Myocardial infarction related to percutaneous coronary intervention (Type 4a), Myocardial infarction related to stent thrombosis (Type 4b), Myocardial infarction related to coronary artery bypass grafting (Type 5) [28].

Morphologically myocardial infarction is distinguished in transmural infarction and subendocardial infarction. The first is the usual type of MI with the band necrosis to occupy the whole myocardial thickness and the abnormal function lies in an occlusive thrombus in a main coronary artery. In subendocardial infarction, a less frequent type, necrosis concerns part of the myocardial wall, under the left ventricular endocardium. This type is attributable to a more general circulation disorder [24-26].

Macroscopic pathological alterations recognized 12-24 h after the acute myocardial infarction as stains of hyperemia or light paleness of the area. The next 3-5 h the infarction appears as a soft area surrounded by a thin zone of hyperemia. Microscopic myocardial necrosis is detected 6-12 h after the onset by swelling of muscle cells, loss of transversal lines, karyopyknosis and karyolisis. Pathologically can be defined as acute, healing or healed. The existence of polymorph nuclear leukocytes is characteristic of acute myocardial infarction due to their increased number ( 6 h-7 days). The healing infarction is characterized by the presence of mononuclear cells and fibroblasts and the absence of polymorph nuclear leukocyte (7-28 days). Scar tissue without cellular infiltration is the imprinting of healed infarction (29 days and beyond). The presence of residual scar tissue in the myocardium is evidence of old infarction. Finding typical changes in the electrocardiogram is observed by measuring specific proteins which are released into the blood when the muscle is destroyed. Phosphokinase CPK, isoenzyme CPK-MB and troponin are diagnostic enzymes. Sudden cardiac deaths due to myocardial infarction are due to the occurrence of ventricular fibrillation of a disorder of the stimulus transmitted by damaged myocardial cells and lead to totally abnormal abdominal contractions that are ineffective for the production of blood flow. The repairing and remodelling mechanisms are included the exosomes which are an emerging treatment for the myocardial infarction as they can mediate cellular-, tissue-, and organlevel micro communication under normal and pathological condition $[20,24,29]$.

\section{Immunohistochemistry}

Immunohistochemistry is a technique based on antigen-antibody binding and on the principles of immunology and chemistry. It relies on the process of identifying antigenic epitopes from monoclonal or polyclonal ant bodies [30-46,50]. The biochemical reactions that take place render the result visible. Different antigens correspond in different cell lines and tissues [51-60]. In conclusion it is a specialized technique by which a distinction is made between physiological and pathological parts of tissues and questions with a genetic background can be answered [47-49,57,58,61].

The method is sensible and specific and can be used in formalinfixed, paraffin-embedded tissues. The above features give a competitive advantage over the other diagnostic methods. Particular attention needs to be paid to the correct stabilization of the tissues, the markers used and the staining. In this way, the sample remains unspoken and the results are interpreted with greater precision. Chromogens are used to quantitate the enzyme reaction and the concentration of products $[47,48,51,52,59,60]$.
Better analysis of post-mortem diagnosis is a primary goal. It is necessary to understand and evaluate the myocardial infarction and ischemic heart disease. In specimens corresponding to cases of myocardial infarction, there are differences in tissue's pathophysiology and in the form of muscle fibres as it emerged from the cell death. These changes can be evaluated by the immunohistochemistry method, highlighting the different ways of reacting multiple cell antibodies. It is also possible to place the myocardial infarction in a timeline according to the time that has occurred $[49,50,54,58]$.

In addition cardiac proteins released into the circulation of blood can be characterized as cellular antigens. A combination of markers and antibodies is needed for adequate evidence of myocardial necrosis and final diagnosis. Loss of staining reflects an early stage. Myocardial infarction is better characterized by immunohistochemistry as the latter facilitates precise analysis of structural organization in connection with the chemistry of cells and tissue engineering. With the use of sensitive, specific markers, controls and antibodies against proteins and in coordination with the intensity of staining myocardial areas are outlined and determined $[53,55,56]$.

\section{Real-Time Polymerase Chain Reaction}

Real Time PCR is used for fast and accurate quantification of RNA and DNA. This technique allows the detection of sequence and point mutations, the measurement of products' quantity and the monitoring of the rate at which a target molecule is amplified in real time. Initially, the product is not detectable, because it is in very small quantities. This stage is followed by the multiplication phase of the product (nearly doubled in each signal). The more molecular targets are initially available, the fewer cycles will be required to start the exponential phase [57-62].

If we compare the number of cycles that needed more than one reaction to reach their exponential phase, we can determine how many molecules were used as a template initially. To determine each cycle's product there are several approaches, but all based on the detection of fluorescent label (tag), which binds to each synthesized molecule [57-62].

\section{Taq-man}

This method is based on probe hydrolysis from Taq-polymerase. Firstly, two probes are made, one for each SNP (A/T or G/C). Then PCR is applied and depending and depending on the color we conclude: The probe having mismatch, is not cleaved by the exonuclease property of polymerase. The probe who sticks is cleaved [57-62].

\section{SYBR-green}

Fluorescent dye is used, which inserts the double strand of the produced PCR product. When DNA is decomposed, a pigment is released. When DNA is composed, it binds and phosphoresces [57-62].

\section{Fluorescence resonance energy transfer}

This method uses two probes, each hybridized very close to the other. The upstream probe is labeled at the 3 ' end with a fluorescent donor-molecule and the downstream at the 5'end with a fluorescent acceptor-molecule [57-62]. 


\section{Conclusions}

To sum up, cardiac muscle is one of the most important organs of human body and its function sometimes can be unbalanced due to some disruptions. This fact can cause problems which may even lead to death. For example, cardiac infarction is a major cause of death and it has many details and factors which determine both the cause and the time that happened. The five types of infarction which are described above have specific symptoms, but if it comes to death, there are details which make the difference and they have to be examined further. Most of the times a macroscopic post-mortem examination is not enough to give answers. Molecular biology and molecular techniques can help to find these details. Technology and science progress are able to combine methods, techniques and protocols to provide accurate and specific answers about infarction.

\section{References}

1. Keith LM, Arthur FD, Anne MR (2013) Clinical anatomy. Broken Hill Publishers, Nicosia, Cyprus.

2. Freceric HM, Michael JT (1995) Human anatomy. Prentice Hall, New Jersey, USA.

3. Florin MF (2014) Atlas of Heart Anatomy and Development. London, Springer-Verlag, London.

4. Richard EK (2012) Cardiovascular Physiology Concepts (2nd Edtn) Lippincott Williams \& Wilkins, Wolter Kluwer business Baltimore, USA.

5. Moini J (2016) Anatomy and Physiology for Health Professionals (2nd Edtn). India.

6. Syed S, Gopinath G, Jeanette SC, John RB (2009) Integrading Cardiology for Nuclear Medicine Physicians. Springer, Berlin, Heidelberg.

7. Arthur CG, John EH (2006) Textbook of Medical Physiology (11th edtn). Elsevier Philadelphia, Pennsylvania.

8. Kim EB, Susan MB, Scott BH (2014) Ganong's Review of Medical Physiology. Broken Hill Publishers, Nicosia, Cyprus.

9. Rodney AR, David RB (2015) Medical Physiology, Principles for Clinical Medicine (4th edtn). Rotonda Publishers, Thessaloniki.

10. Robert MA (1993) The Gross Physiology of the Cardiovascular System (2nd edtn). Racquet Press, Tuscon.

11. Vander A, Sherman J, Luciano D, Tsakopoulos M (2011) Human Physiology. Broken Hill Publishers, Nicosia, Cyprus.

12. Bruce SS (2013) Berne \& Levy Physiology. Petamorphosi Attiki, Science Publishers, Parisianos, UK.

13. Michael HR, Edward HR, Lynn JR (1989) Histology: A Text and Atlas. Williams \& Wilkins, USA.

14. Leslie PG, James LH (2000) Color Textbook of Histology (3rd edtn), Athens, Science Editions, Parisianos, Philadelphia.

15. Alan S, James SL (2008) Human Histology. PH Pashalidis Publishers, Philadelphia.

16. William KO, Patrick CN, Frank HN (2011) Histology. PH Pashalidis Publishers, Philadelphia.

17. Anthony LM (2016) Junqueira's Basic Histology (14th edtn). The McGraw-Hill Companies, USA.

18. Vander A, Sherman J, Luciano D, Tsakopoulos M (2011) Human Pathophysiology, The mechanisms of Body Function (8th edtn), Broken Hill Publishers, Nicosia, Cyprus.

19. Andreoli TE, Carprenter CJ, Plum F, Smith LH (1991) Cecil Essentials of Medicine, WB Sauderns Company.

20. Rajan P, Christopher MK (2010) Cardiovascular Magnetic Resonance, Acute Myocardial Infarction: Ventricular Remodeling (2nd edtn). Churchill Livingstone, USA

21. Donaldson C, Dauerman HL (2013) Acute Myocardial Infarction, Critical Care Secrets (5th edtn). Elsevier, USA.
22. Cohn JN, Wilson Colucci WS (2006) Cardiovascular Effects of Aldosterone and Post-Acute Myocardial Infarction Pathophysiology. Am J Cardiol 97: 4-12.

23. Frangogiannis NG (2015) Pathophysiology of Myocardial Infarction Compr Physiol 5:1841-75.

24. Sivridis E (2007) Pathological Anatomy. Medical Publishers PH Pashalidis, Philadelphia.

25. Fineschi V, Baroldi G, Malcolm DS (2006) Pathology of the Heart and Sudden Death in Forensic Medicine. CRC Press, Abingdon.

26. Pfeffer MA, Braunwald E (1990) Ventricular remodeling after myocardial infarction. Experimental observations and clinical implications. Circulation 81:1161-1172.

27. Lu L, Liu M, Sun R, Zheng Y, Zhang P (2015) Myocardial infarction: Symptoms and treatments. Cell Biochemistry Biophysics 72: 865-7.

28. Saaby L, Poulsen TS, Hosbond S, Larsen TB, PyndtDiederichsen AC, et al. (2013) Classification of myocardial infarction: Frequency and features of type 2 myocardial infarction. The American J Med 126: 789-97.

29. Sahoo S, Losordo DW (2014) Exosomes and cardiac repair after myocardial infarction. Circ Res 114: 333-44.

30. Weksberg R, Hughes S, Moldovan L, Bassett A, Chow E et al. (2005). A method for accurate detection of genomic microdeletions using real-time quantitative PCR.BMC Genomics 6: 180.

31. Gibson U, Heid C, Williams P (1996) A novel method for real time quantitative RT-PCR. Genome Res 6: 995-1001.

32. Klein D (2002) Quantification using real-time PCR technology: Applications and limitations. Trends In Molecular Medicine 8: 257-260.

33. Vandesompele J, De Preter K, Pattyn F, Poppe, B, Van Roy, et al. (2002) Accurate normalization of real-time quantitative RT-PCR data by geometric averaging of multiple internal control genes. Genome Biology 3: 34

34. Bustin S (2005) Quantitative real-time RT-PCR - A perspective. J Mol Endocrinol 34: 597-601.

35. Wu J (2003) Molecular imaging of cardiac cell transplantation in living animals using optical bioluminescence and positron emission tomography. Circulation 108: 1302-1305.

36. Van de Pol A, Wolfs T, Jansen N, van Loon A, Rossen J (2006). Critical Care 10: R61.

37. Moniotte S, Vaerman J, Kockx M, Larrouy D, Langin D, et al. (2001) Realtime RT-PCR for the detection of beta-adrenoceptor messenger rnas in small human endomyocardial biopsies. J Mol Cellular Cardio 33: 2121-2133.

38. Ramakers C, Ruijter J, Deprez R, Moorman A (2003) Assumption-free analysis of quantitative real-time polymerase chain reaction (PCR) data. Neurosci Let 339: 62-66.

39. Pfaffl M (2001) A new mathematical model for relative quantification in real-time RT-PCR. Nucleic Acids Res, 29: 45e-45.

40. Lekanne Deprez R, Fijnvandraat A, Ruijter J, Moorman A (2002) Sensitivity and accuracy of quantitative real-time polymerase chain reaction using SYBR green I depends on CDNA synthesis conditions. Anal Biochem 307: 63-69.

41. Jefferies R, Morgan E, Shaw S (2009). A SYBR green real-time PCR assay for the detection of the nematode Angiostrongylus vasorum in definitive and intermediate hosts. Vet Parasitol, 166: 112-118.

42. Ponchel F, Toomes C, Bransfield K, Leong F, Douglas S, et al (2003). Real-time PCR based on SYBR-Green I fluorescence: An alternative to the TaqMan assay for a relative quantification of gene rearrangements, gene amplifications and micro gene deletions. BMC Biotechnol 3: 18.

43. Malinen E, Kassinen A, Rinttilä T, Palva A (2003) Comparison of realtime PCR with SYBR Green I or 5'-nuclease assays and dot-blot hybridization with rDNA-targeted oligonucleotide probes in quantification of selected faecal bacteria. Microbiology 149: 269-277.

44. Sacerdoti F (2018) Advanced imaging techniques in clinical pathology. 
45. Grant SA, Pierce ME, Lichlyter D, Grant D (2005) Effects of immobilization on a FRET immunosensor for the detection of myocardial infarction. Anal Bioanal Chem 381: 1012-1018.

46. Nagai T, Miyawaki A (2004) A high-throughput method for development of FRET-based indicators for proteolysis. Biochem Biophys Res Commun 319: 72-77.

47. Kiparidou E, Tinga A (2007) Immunohistochemistry Clinical Oncology, General Part, EEPOE Athens.

48. McCourt CM, Boyle D, James J, Salto-Tellez M (2013) Immunohistochemistry in the era of personalised medicine, J Clin Pathol Jan 66: 58-61.

49. Taylor CR, Levenson RM (2006) Quantification of immunohistochemistry-issues concerning methods, utility and semiquantitative assessment II, Histopathology 49: 333-447.

50. Tatić V, Rafajlovski S, Kanjuh V, Gajanin R, Suscević D, et al. (2012) Histochemical and immunohistochemical analyses of the myocardial scar fallowing acute myocardial infarction. Vojnosanit Pregl 69: 581-8

51. Ramos-Vara JA (2005) Technical aspects of immunohistochemistry. Vet Pathol 42: 405-426.

52. Battifora H (2013) Quality assurance issues in immunohistochemistry, J Histotech 22: 169-175

53. Mori H, Cardiff RD (2016) Methods of immunohistochemistry and immunofluorescence: Converting invisible to visible, methods in molecular biology. 1458: 1-12.

54. Stack EC, Wang C, Roman KA, Clifford C, Hoyt C (2014) Multiplexed immunohistochemistry, imaging, and quantitation: A review, with an assessment of Tyramide signal amplification, multispectral imaging and multiplex analysis. Method 70: 46-58.
55. Hayat MA (2002) Microscopy, Immunohistochemistry and Antigen Retrieval Methods For Light and Electron Microscopy. For Light and Electron Microscopy, Kluwer Academic Publishers.1: 1-6

56. Jia JZ, Shen YW, Xue AM, Zhao ZQ (2015) Immunohistochemical analysis of cardiac troponin inhibitor in an experimental model of acute myocardial infarction experimental model and in human tissues. Pathol Res Pract 211: 456-61.

57. Ramos-Vara JA, Miller MA (2014) When tissue antigens and antibodies get along: Revisiting the technical aspects of immunohistochemistry--the red, brown, and blue technique. Vet Pathol 51: 42-87.

58. Shi SR, Shi Y, Taylor CR (2011) Antigen retrieval immunohistochemistry: Review and future prospects in research and diagnosis over two decades. J Histochem Cytochem 59: 13-32.

59. Chris M (2013) Chromogens in Multiple Immunohistochemical Staining Used for Visual Assessment and Spectral Imaging: The Colorful Future. J Histotec 33: 31-40.

60. Bedeković T, Lemo N, Lojkić I, Beck A, Lojkić M, Madić J (2011) Implementation of immunohistochemistry on frozen ear notch tissue samples in diagnosis of bovine viral diarrhea virus in persistently infected cattle. Acta Vet Scand 53: 65.

61. Torlakovic EE, Nielsen S, Vyberg M, Taylor CR (2015) Getting controls under control: The time is now for immunohistochemistry. J Clin Pathol 68: 879-88.

62. Bi H, Yang Y, Huang J, Li Y, Ma C, et al. (2013) Immunohistochemical detection of S100A1 in the postmortem diagnosis of acute myocardial infarction. Diagn Pathol 8: 84. 